This manuscript is a preprint and will be submitted for publication in Computers and Geosciences. Please note that, despite having undergone peer-review, the manuscript has yet to be formally accepted for publication. Subsequent versions of this manuscript may have slightly different content. If accepted, the final version of this manuscript will be available via the 'Peer-reviewed Publication DOI' link on the right-hand side of this webpage. Please feel free to contact any of the authors; we welcome feedback 


\section{Sedimentary structures discriminations with hyperspectral imaging on}

\section{sediment cores}

Kévin Jacq ${ }^{1,2}$, William Rapuc ${ }^{1}$, Alexandre Benoit ${ }^{2}$, Didier Coquin ${ }^{2}$, Bernard Fanget ${ }^{1}$, Yves Perrette $^{1}$, Pierre Sabatier ${ }^{1}$, Bruno Wilhelm ${ }^{3}$, Maxime Debret ${ }^{4}$, Fabien Arnaud ${ }^{1}$

1 Laboratoire des Environnements, DYnamiques, TErritoires de la Montagne, Université Savoie MontBlanc, UMR CNRS 5204,73376 Le Bourget du Lac, France

2 Laboratoire d'Informatique, Systèmes, Traitement de l'Information et de la Connaissance (LISTIC), Université Savoie Mont-Blanc, 74944 Annecy Le Vieux Cedex, France

3 Institute for Geosciences and Environmental Research, University Grenoble Alpes, CNRS, IRD,

Grenoble, France

4 Laboratoire de Morphodynamique Continentale et Côtière, Université de Rouen, UMR CNRS 6143, 76821 Mont-Saint-Aignan, France, Université de Caen, UMR CNRS 6143, 14000 Caen, France

Corresponding Author:

Kévin Jacq

UMR CNRS 5204 Environnements, Dynamiques et Territoires de la Montagne (EDYTEM)

Université Savoie Mont Blanc, Campus scientifique,

73376 Le Bourget du Lac cedex, France

jacq.kevin@hotmail.fr 


\section{Abstract}

Hyperspectral imaging (HSI) is a non-destructive high-resolution sensor, which is currently under significant development to analyze geological areas with remote devices or natural samples in a laboratory. In both cases, the hyperspectral image provides several sedimentary structures that need to be separated to temporally and spatially describe the sample. Sediment sequences are composed of successive deposits (strata, homogenite, flood) that can be visible or not depending on sample properties. The classical methods to identify them are time-consuming, have a low spatial resolution (millimeter), and are generally based on a naked-eye counting. In this study, we propose to compare several supervised classification algorithms for the discrimination of sedimentological structures on lake sediments. Instantaneous events in lake sediments are generally linked to extreme geodynamical events (e.g., floods, earthquakes), their identification and counting are essential to understand long-term fluctuations and improve hazard assessments. This is done by reconstructing a chronicle of event layer occurrence, including estimation of deposit thicknesses. Here we applied two hyperspectral imaging sensors (Visible Near-Infrared VNIR, $60 \mu \mathrm{m}, 400-1000 \mathrm{~nm}$; Short Wave Infrared SWIR, $200 \mu \mathrm{m}, 1000-2500 \mathrm{~nm}$ ) on three sediment cores from different lake systems. We highlight that the SWIR sensor is the optimal one to create robust classification models with discriminant analyses. Indeed, the VNIR sensor is impacted by the surface reliefs and structures that are not in the learning set, which lead to miss-classification. These observations are also valid for the combined sensor (VNIR-SWIR). Several spatial and spectral pre-processing were also compared and allowed to highlight discriminant information specific to a sample and a sensor. These works show that the combined use of hyperspectral imaging and machine learning improves the characterization of sedimentary structures in laboratory conditions.

Keywords: Hyperspectral Imaging, Machine Learning, Discrimination methods, Visible and NearInfrared Spectroscopy, Automatic Detection, Sedimentary Deposits 


\section{Introduction}

Natural archives, such as sediment cores are composed of a succession of deposits recording past climate and environment biological-physical-chemical variations. There are two main processes; continuous sedimentation that can be interrupted by event layers. The continuous sedimentation allows to create an age-depth model and infer the environment and climate conditions. The event layers, e.g., related to floods (Gaume et al., 2009; Glur et al., 2013), storms (Sabatier et al., 2012), landslides, earthquakes (Wilhelm et al., 2016), tsunamis (Chagué-Goff, 2010), eruptions, record among the most damaging disasters in terms of economic and societal losses. Currently, in an overwhelming majority of laboratory studies on natural archives, the sedimentary structures are first described visually, then numerous physical (X-ray imaging, computed tomography scan, grain-size) and chemical analyses are undertaken. From those results, the event layers are identified and described. Then, layers with the same characteristics (e.g., color and texture) are usually counted by naked-eye observation. This approach is time-consuming, characterized by a low spatial resolution and subject to high uncertainties due to human interpretations (Lotter and Lemcke, 1999). To overcome these limits, several semi-automatic methods were developed to discriminate these sedimentary deposits from RGB images. The main approaches studied the strata from annually laminated sediment to create an age model with their discretization, but they only use a line or a combination of segments, and then a deposit is characterized by the detection of the maxima (Meyer et al., 2006; Weber et al., 2010). Similarly, for the automatic detection of event layers, Vannière et al. (2013) proposed to use a 1/Red signal and threshold. Some studies also used discrimination methods based on labeled pixels to create classification maps, for example, an adaptive neuro-fuzzy inference system (Ebert and Trauth, 2015) or K-nearest neighbor (Ndiaye et al., 2012). Thereby, only the color signal has been investigated, while many other parameters are potentially useful to distinguish event layers, such as texture, grain-size, chemical composition (Fouinat et al., 2017; Gilli et al., 2013; Wilhelm et al., 2018). A more relevant approach would then consist to detect event layers considering all these parameters automatically. 
Hyperspectral imaging (HSI) is a non-destructive high-resolution laboratory analysis, which allows a semi-automatic description of the natural deposits based on their physical-chemical characterization. HSI can improve chemical knowledge by analyzing the sample surface. It has already been used to characterize mineralogical fingerprints (Feng et al., 2018; Lorenz et al., 2019; Tusa et al., 2020), organic matter (Jacq et al., 2019b; Van Exem et al., 2019), pigments (Butz et al., 2017; Makri et al., 2020; Schneider et al., 2018), and particle size distribution (Jacq et al., 2019a). Some of these studies highlight sedimentary structures with proxy's estimation but without characterizing them spatially. It has also permitted to characterize spatial variations of volcanic tephra layers with a visible and nearinfrared hyperspectral camera (VNIR, 400-1000 nm) using a supervised classification method based on an artificial neural network (Aymerich et al., 2016).

In this study, we propose to test several discrimination methods based on artificial neural networks (ANN), on classification rules (decision tree DT, random forest RF) and classification models (linear and quadratic discriminant analysis LDA/QDA, partial least squares discriminant analysis PLS-DA). The hyperspectral images used in this study come from a visible and near-infrared camera (VNIR, pixel size: $60 \mu \mathrm{m}$ ) and a short-wave infrared sensor (SWIR, pixel size: $200 \mu \mathrm{m})$. The two sensors can also be combined to estimate a VNIR-SWIR composite sensor (pixel size: $200 \mu \mathrm{m}$ ) or reduced to determine pseudo-RGB, HSV, Lab, and grayscale images. Several spectral and spatial pre-processing, and compression algorithms were also compared to improve the discrimination of continuous sedimentation and event layers. Consequently, this study proposes to compare three high-resolution images, seven discrimination methods, raw data, and eight pre-processing to create discrimination models between the continuous sedimentation and event layers.

\section{Materials and methods}

\subsection{Sample sites description}



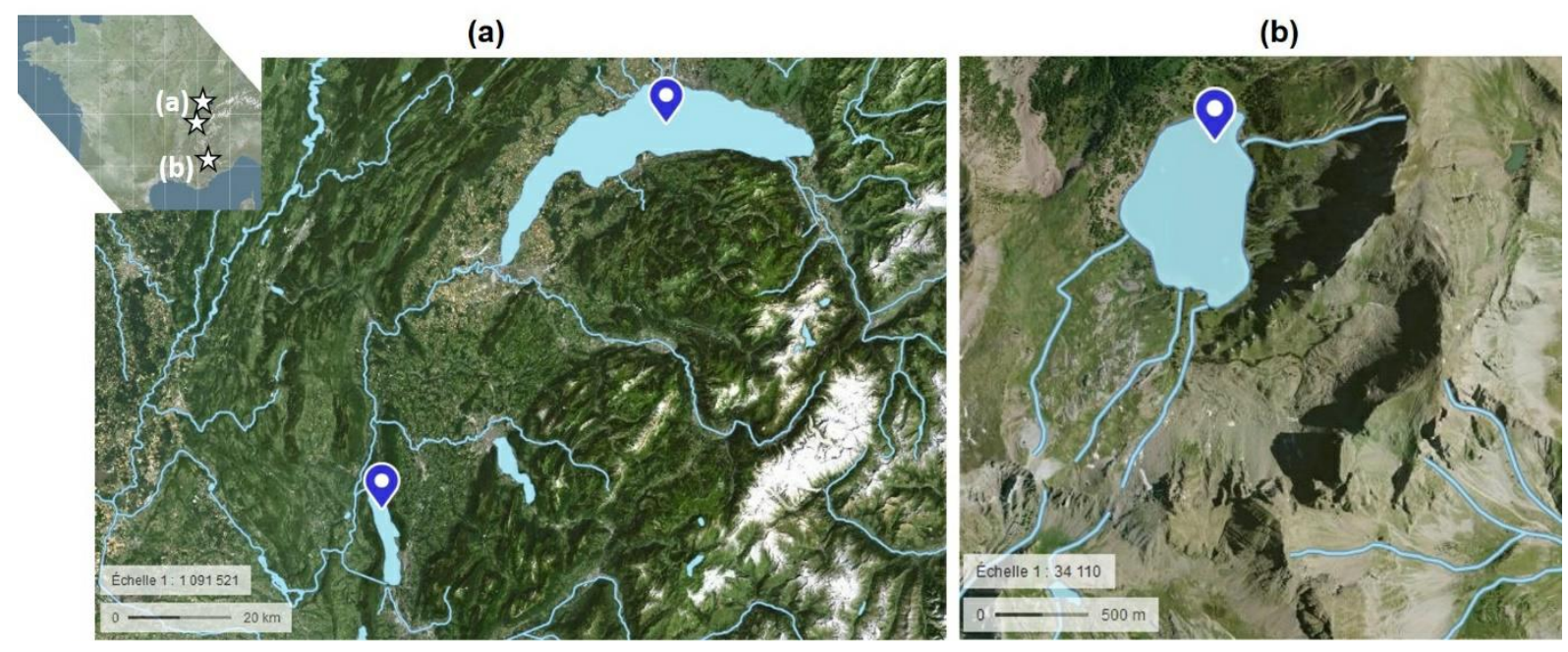

Figure 1: Locations, tributaries and effluents of the lakes: (a) Bourget and Geneva, (b) Allos

Three sediment cores were chosen from three lakes located in the western French Alps (Figure 1) in different watersheds, presenting different geological contexts and different surface areas to present event layers with different geochemical compositions. The studied cores were retrieved from lake Allos (ALO09_P13, IGSN: IEFRA08JN, coring year: 2009) (Wilhelm et al., 2015, 2012) from the deep basin of lake Le Bourget (LDB17_P11, coring year: 2017) (Jenny et al., 2014b) and from lake Geneva (LEM10, IGSN: IEFRA008N, coring year: 2010) (Jenny et al., 2014a).

For the three selected cores, the sediment was first described and logged after naked-eye observations. When they were available, the event layers were distinguished from the continuous sedimentation by using sedimentological and geochemical results. As X-ray fluorescence core-logging that was made at $1 \mathrm{~mm}$ resolution for ALO09 and $0.5 \mathrm{~mm}$ resolution for LDB17, which was interesting to have a higher resolution than with naked eye. Once clearly identified, those layers were counted visually. In ALO09 and LDB17, the sediment sequence consists of homogeneous light gray clay alternating with dark layers, interpreted as flood induced deposits. Whereas for LEM10, the event layers present a pale red color. In the three cores, the frequency, and the thickness of event deposits is variable (Table 1). After that, the data sets will be referred to by the lake name, but it must be understood that from one core to another from the same site, there may be differences (color, chemical, physical). 
Table 1: Statistics of the naked eye event layer detections. $N$ is the number of event layers identified in each lake core, and the other variables are statistics about layer thickness.

\begin{tabular}{|l|l|l|l|l|l|}
\cline { 2 - 6 } \multicolumn{1}{c|}{} & $\mathrm{N}$ & $\begin{array}{l}\text { Average } \\
(\mathrm{mm})\end{array}$ & $\begin{array}{l}\text { Standard deviation } \\
(\mathrm{mm})\end{array}$ & $\begin{array}{l}\text { Minimum } \\
(\mathrm{mm})\end{array}$ & $\begin{array}{l}\text { Maximum } \\
(\mathrm{mm})\end{array}$ \\
\hline Allos & 69 & 7.44 & 5.73 & 1.00 & 39.00 \\
\hline Bourget & 56 & 3.41 & 2.17 & 1.00 & 11.00 \\
\hline Geneva & 15 & 15.93 & 21.97 & 3.00 & 88.00 \\
\hline
\end{tabular}

2.2 VNIR and SWIR Hyperspectral Image acquisition

Two hyperspectral reflectance cameras were used to analyze these cores thanks to the UMR CNRS $\mathrm{M} 2 \mathrm{C}$ lab facilities, University of Normandie-Rouen (France). They cover two consecutive spectral ranges from $400 \mathrm{~nm}$ to $1000 \mathrm{~nm}$ (Visible and Near-Infrared, VNIR) and from $968 \mathrm{~nm}$ to $2574 \mathrm{~nm}$ (Short Wave InfraRed, SWIR). They have a theoretical spatial resolution of $60 \mu \mathrm{m}$ and $200 \mu \mathrm{m}$, respectively. The real resolution may vary due to surface roughness. Relevant data were obtained with a flattening and a cleaning of the core to have a plane surface that reveals sediment structures (Butz et al., 2015). Then, a calibration of the camera was realized with a spectralon reference, and the image of a known object to have squared pixels (true shape) and relevant reflectance intensities (color and signal to noise ratio).

The resolution of the two datasets (VNIR and SWIR) has also been homogenized at a common spatial resolution of $200 \mu \mathrm{m}$ to get a VNIR-SWIR image. The combination of the two HSI into a unique one (i.e., VNIR-SWIR) was made with image registration (Liu et al., 2011) adapted to HSI with a registration on a wavelength plane characteristic of a similar chemical compound. In previous work, we find that the $970 \mathrm{~nm}$ (VNIR) and $1200 \mathrm{~nm}$ (SWIR) wavelengths were optimal to combine them (Jacq et al., 2019c). They are related to hydroxyl chemical bonds mostly associated with moisture for sediment cores (Bull, 1991; Viscarra Rossel and Behrens, 2010). Therefore, a composite sensor was created to merge the VNIR and SWIR datasets to cover the range of $400-2500 \mathrm{~nm}$. In this study, we compare the classification performances of three datasets: VNIR at a spatial resolution of $60 \mu \mathrm{m}$, SWIR at $200 \mu \mathrm{m}$, and VNIR-SWIR at $200 \mu \mathrm{m}$. 
Pre-processing can be used to correct the data from noise or aberrant values, and to highlight discriminant wavelengths. With the three dimensions of the HSI, spectral, and spatial pre-processing can be used (Rinnan et al., 2009; Vidal and Amigo, 2012). Spectral pre-processing compared in this study are normalization (autoscale), baseline correction (detrend), scattering effect correction (Standard Normal Variate (SNV) and Multiplicative Scatter Correction (MSC)) (Barnes et al., 1989), Savitzky-Golay derivatives (Savitzky and Golay, 1964). Principal Component Analysis (PCA) was also used as a compression of the spectral dimension (Pearson, 1901). Contrast Limited Adaptive Histogram Equalization (CLAHE) was used on the spatial dimensions with an estimation on the grayscale image levels and applied on each image wavelength (Zuiderveld, 1994).

\subsection{Data Analysis}

Seven commonly used machine learning algorithms were used to create classification models with three spectral type data (VNIR, SWIR, VNIR-SWIR) (Figure 2). First, an RGB image was made from the VNIR HSI to label continuous sedimentation and event layer pixels. Then, machine learning methods were used to estimate discrimination models. Also, eight pre-processing (spatial and spectral) were used and compared with raw data. Consequently, 189 discriminations models were created for each sample to find the optimal sensor (of three) -methods (of seven) -pre-processing (of nine). The Matlab codes used in this study are available in github.com/JacqKevin/HSI_SupervisedClassification. 


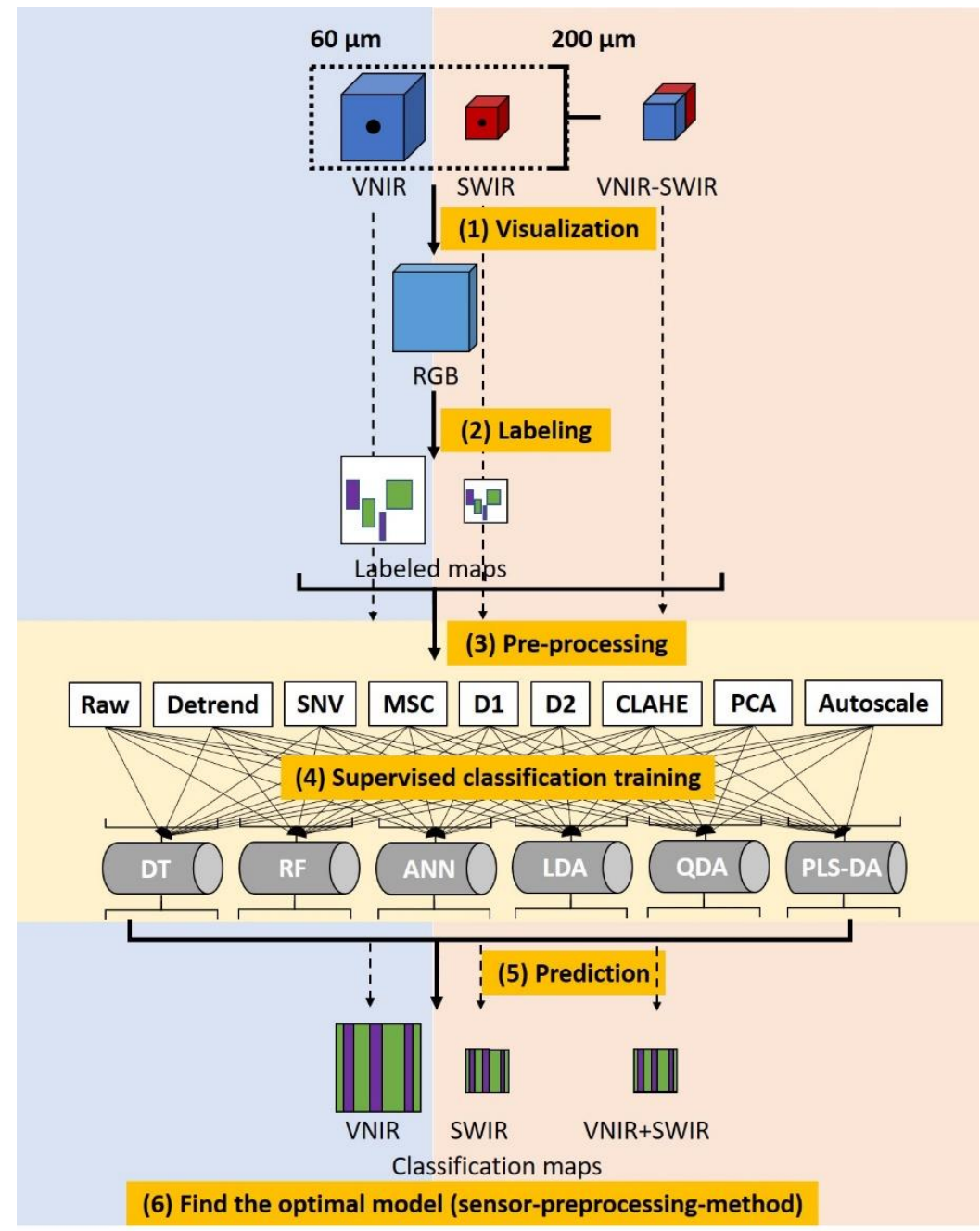

Figure 2: Data processing for the creation of a classification model to predict each pixel: (1) Visualization with RGB images at both resolutions; (2) Manual labeling of the image; (3) Data pre-processing and (4) Creation of the supervised classification models for each dataset (DT: Decision Tree, RF: Random Forest, ANN: Artificial Neural Network, LDA: Linear Discriminant Analysis, QDA: Quadratic Discriminant Analysis, PLS-DA: Partial Least Squares Discriminant Analysis); (5) Prediction for each image; (6) Estimation of the optimal model depending on the sensor, the pre-processing and the discrimination model.

\subsubsection{Data labeling}

The hyperspectral VNIR data can be reduced to three planes corresponding to a Red-Green-Blue image of the VNIR sensor (611-549-464 nm, according to sRGB standard) (CIE, 1999). The RGB images are representation modes adapted for eye vision and were used to visualize the sample for the labeling of the sedimentary structures. For that, the user must manually select rectangle areas that correspond to the different studied classes based on the known deposits characterized by 
geochemical, textural, and mineralogical analysis. The resulting maps were used as a mask with 0 values for non-labeled pixels and other values for labeled pixels (1: event layer, 2: continuous sedimentation). It was also used to extract the labeled pixels and their corresponding spectrum. For the SWIR dataset, these maps were also made with the VNIR data at $60 \mu \mathrm{m}$ and resized at $200 \mu \mathrm{m}$.

\subsubsection{Classification modeling}

Seven methods were used to create a supervised classification model to discriminate the two sedimentary processes (Figure 3). Decision tree (DT) and random forest (RF) are linear nonparametric methods based on successive rules on the reflectance value of one wavelength at a time (Breiman et al., 1984; Ho, 1995). Artificial neural networks (ANN) are non-linear parametric methods based on data learning with neurons (Ivakhnenko and Lapa, 1965; McCulloch and Pitts, 1943; Rosenblatt, 1958). Linear, Quadratic, and Partial Least Squares Discriminant Analysis (LDA, QDA, PLSDA) are parametric methods with a mathematical function kernel to separate the classes (Fisher, 1936; Wold et al., 1984).

(a) Rule-based methods

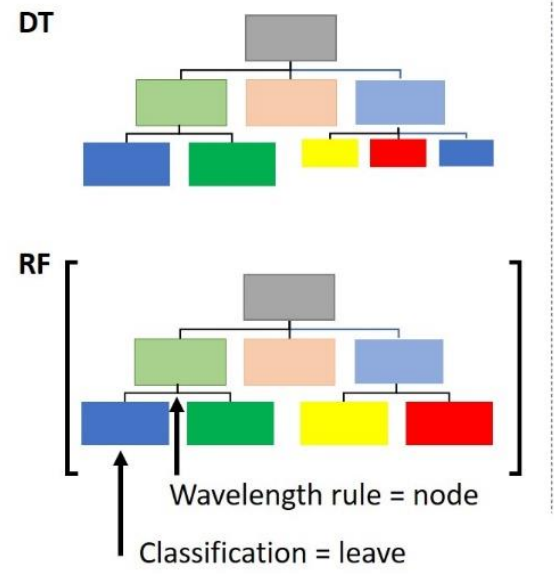

(b) Neuron-based methods

ANN

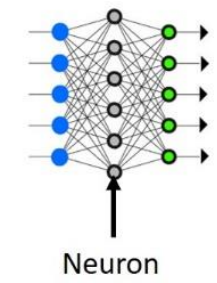

(c) Function-based methods LDA, PLS-DA

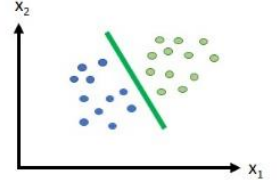

QDA

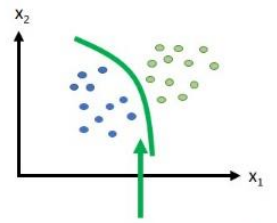

Discriminant function

Figure 3: Schematic representation of the machine learning methods used in this study depending on their basis: (a) rules, (b) neurons, (c) functions.

The models were fitted with $70 \%$ randomly selected data in calibration and the remaining in the test set (Table 2). This ratio was applied to the class with the smaller number of labeled pixels to have a 
consistent number on each group. The same calibration and test sets were used for each classification method, but they were different for each pre-processing. The labeled pixels number depends on the ability of the user to see precisely the deposits, so only pixels that we are sure they belong to these classes are labeled so as not to introduce uncertainty with bad labeling. Due to the compression of the high-resolution labeled map, the pixels of the contours may have been removed as being uncertain, which slightly changes the labeling percentages between the two resolutions. That explains the difference between the cores with labeled pixels between $0.45 \%$ and $15.71 \%$ for one class (Table 2). It will also allow to see the learning capacity depending on the number of calibration pixels.

Table 2: Pixel number for each sediment core image and labeled pixels for the calibration and validation sets for each class (1=event layer, 2=continuous sedimentation)

\begin{tabular}{|c|c|c|c|c|c|c|}
\hline Sample & Sensors & Total pixels & Class & $\begin{array}{l}\text { Number of the area } \\
\text { labeled and pixels }\end{array}$ & $\begin{array}{l}\text { Calibration } \\
\text { pixels }\end{array}$ & $\begin{array}{l}\text { Validation } \\
\text { pixels }\end{array}$ \\
\hline \multirow{4}{*}{ Allos } & \multirow{2}{*}{ VNIR } & \multirow{2}{*}{$30,433,152$} & 1 & $\begin{array}{l}8 \text { areas, } \\
598,722(1.97 \%)\end{array}$ & $\begin{array}{l}419,105 \\
(1.38 \%)\end{array}$ & $\begin{array}{l}179,617 \\
(0.59 \%)\end{array}$ \\
\hline & & & 2 & $\begin{array}{l}6 \text { areas, } \\
961,079(3.16 \%)\end{array}$ & $\begin{array}{l}419,105 \\
(1.38 \%)\end{array}$ & $\begin{array}{l}541,974 \\
(1.78 \%)\end{array}$ \\
\hline & \multirow{2}{*}{$\begin{array}{l}\text { SWIR, } \\
\text { VNIR-SWIR }\end{array}$} & \multirow{2}{*}{$1,702,476$} & 1 & $\begin{array}{l}8 \text { areas, } \\
35,364(2.08 \%)\end{array}$ & $\begin{array}{l}24,755 \\
(1.45 \%)\end{array}$ & $\begin{array}{l}10,609 \\
(0.62 \%)\end{array}$ \\
\hline & & & 2 & $\begin{array}{l}8 \text { areas, } \\
56,261(3.30 \%)\end{array}$ & $\begin{array}{l}24,755 \\
(1.45 \%)\end{array}$ & $\begin{array}{l}31,506 \\
(1.85 \%)\end{array}$ \\
\hline \multirow{4}{*}{ Bourget } & \multirow{2}{*}{ VNIR } & \multirow{2}{*}{$21,096,723$} & 1 & $\begin{array}{l}12 \text { areas, } \\
155,876(0.74 \%)\end{array}$ & $\begin{array}{l}68,636 \\
(0.33 \%)\end{array}$ & $\begin{array}{l}87,240 \\
(0.04 \%)\end{array}$ \\
\hline & & & 2 & $\begin{array}{l}9 \text { areas, } \\
98,051(0.46 \%)\end{array}$ & $\begin{array}{l}68,636 \\
(0.33 \%)\end{array}$ & $\begin{array}{l}29,415 \\
(0.14 \%)\end{array}$ \\
\hline & \multirow{2}{*}{$\begin{array}{l}\text { SWIR, } \\
\text { VNIR-SWIR }\end{array}$} & \multirow{2}{*}{$1,806,624$} & 1 & $\begin{array}{l}12 \text { areas, } \\
12,975(0.72 \%)\end{array}$ & $\begin{array}{l}5,709 \\
(0.32 \%)\end{array}$ & $\begin{array}{l}7,266 \\
(0.40 \%) \\
\end{array}$ \\
\hline & & & 2 & $\begin{array}{l}9 \text { areas, } \\
8,156(0.45 \%)\end{array}$ & $\begin{array}{l}5,709 \\
(0.32 \%)\end{array}$ & $\begin{array}{l}2,447 \\
(0.14 \%)\end{array}$ \\
\hline \multirow{4}{*}{ Geneva } & \multirow{2}{*}{ VNIR } & \multirow{2}{*}{$13,711,712$} & 1 & $\begin{array}{l}8 \text { areas, } \\
2,034,596(14.84 \%)\end{array}$ & $\begin{array}{l}65,769 \\
(0.48 \%) \\
\end{array}$ & $\begin{array}{l}1,968,827 \\
(14.36 \%) \\
\end{array}$ \\
\hline & & & 2 & $\begin{array}{l}3 \text { areas, } \\
93,956(0.69 \%)\end{array}$ & $\begin{array}{l}65,769 \\
(0.48 \%)\end{array}$ & $\begin{array}{l}28,187 \\
(0.21 \%)\end{array}$ \\
\hline & \multirow{2}{*}{$\begin{array}{l}\text { SWIR, } \\
\text { VNIR-SWIR }\end{array}$} & \multirow{2}{*}{865,234} & 1 & $\begin{array}{l}8 \text { areas, } \\
135,933(15.71 \%)\end{array}$ & $\begin{array}{l}4,078 \\
(0.47 \%)\end{array}$ & $\begin{array}{l}131,855 \\
(15.24 \%)\end{array}$ \\
\hline & & & 2 & $\begin{array}{l}3 \text { areas, } \\
5,826(0.67 \%)\end{array}$ & $\begin{array}{l}4,078 \\
(0.47 \%) \\
\end{array}$ & $\begin{array}{l}1,748 \\
(0.20 \%) \\
\end{array}$ \\
\hline
\end{tabular}

\subsubsection{Quantitative assessment of model classification}


The quantitative performances of the classification models are estimated with the accuracy in calibration and prediction:

Accuracy $=\frac{\text { Truepositive }+ \text { Truenegative }}{\text { Truepositive }+ \text { Truenegative }+ \text { Falsepositive }+ \text { Falsenegative }}$

with "true positive" corresponding to class 1 pixels classified in class 1, "true negative" corresponding to class 2 pixels classified in class 2, "false positive" corresponding to class 2 pixels classified in class 1 , and "false negative" corresponding to class 1 pixels classified in class 2.

The accuracy corresponds to class 1 and 2 pixels that are successfully classified in their corresponding classes. Thus, the closer the value is to 1 , the better the prediction.

\subsubsection{Qualitative assessment of each pixel image classification}

The created model must be visually assessed by an expert to quantify the spatial consistency of the classification map because of possible overfitting. For that, the model was used on all the pixels to estimate the classification map. Then, the user must assess it by looking at the salt and pepper characteristics of the image, with single pixels corresponding to potential miss-classification. Also, the user must check the event layer predicted areas with the RGB image. For this, a qualitative index with values between 0 and 5 (arbitrary) is used. For this, a qualitative index with values between 0 and 5 (arbitrary) is used. A value of 0 corresponds to a classification map with mainly a single value for each image pixel. Whereas a value of 5 shows relevant deposits across the image width and a few single pixels.

\section{Results and interpretations}

\subsection{Comparison of the classification methods and the pre-processing}

Eight pre-processing were tested on each sample, each sensor, and each discrimination method to find the optimal combination (Figure 4). The processing must have the capacity to highlight discriminant information and create performant and robust models. PCA and second derivatives (D2) 
present the lowest prediction accuracies for each sensor and sample (Figure 4). The PCA reduction may not keep the discriminant information in the main PCs, as well as the D2. Whereas raw, CLAHE, autoscaled, and detrended data have the highest discriminant properties in all cases (Figure 4). Some pre-processing are sensor dependent, such as SNV and MSC, which models present low accuracies for the VNIR, and high ones for the SWIR sensor. The first derivative (D1) has intermediate accuracies for all cases except for the SWIR sensor and the Allos sample, for which high performances are obtained.

Concerning the discriminant methods, DT presents the lowest prediction accuracies in most of the cases, whereas ANN, QDA, and RF have the highest. For the ANN, few neurons (2-3) seems to be better than numerous. The later has many more parameters and may overfit on the few training data, thus limiting its generalization capability on the test set. The accuracies of the optimal methods are close and must be discussed with all the quantitative values and interpretations of their discriminant spectral properties.

Another consideration to be considered is that the results are sample-specific. They also show that using the LDA or PLS-DA methods with raw data allows to have first performing results, even if adding a pre-processing can slightly improve prediction performances. 


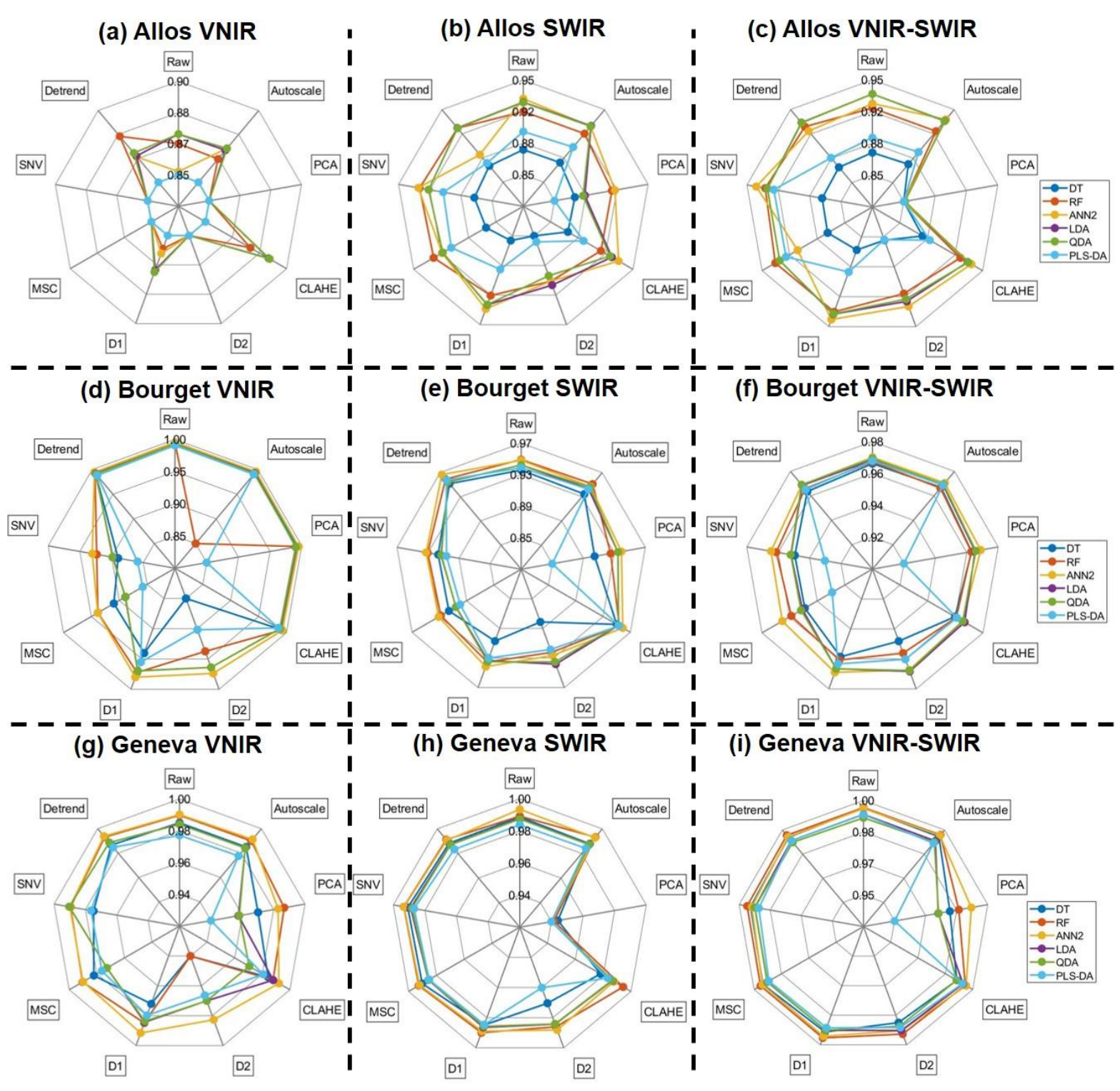

Figure 4: Radar charts of the pre-processing impact on the prediction accuracy for each classification method and lake core hyperspectral images (a-c: lake Allos, d-f: lake Bourget, g-i: lake Geneva; $a, d, g$ : VNIR sensor, $b, e, h$ : SWIR sensor, $c, f, i$ : VNIR-SWIR sensor)

\subsection{Optimal models for each image type}

The optimal model's calibration and prediction accuracies are higher than 0.8 and mainly 0.9 , which highlights the presence of spectral discriminant information in both sensors (Table 3). ANN with two neurons is often the optimal discriminant method based on the prediction accuracy and to be parsimonious because adding neurons do not improve the accuracies. However, for the qualitative index, discriminant analysis methods (LDA, QDA, PLS-DA) generally present the best performance 
levels. The computation time is lower for the LDA, PLS-DA, and DT methods, and all of these methods are fast to compute, so the computation time is not used to select the optimal model. Based on a compromise between these two first properties (accuracies and qualitative), the optimal methods in most of the cases are the LDA or PLS-DA. Another important property is their transparency in the selected discriminant wavelengths. Table 3 highlights an optimal pre-processing that depends mainly on the sample and the sensor. The discrimination methods seem to have a low impact on it, which suggests that an optimal pre-processing can highlight the discriminant wavelengths.

This table also highlights the highest discriminant capacities with the SWIR sensor. The combination of the two sensors, which should be better with the highest amount of spectral information, present intermediate discriminant abilities. Thus, the VNIR data present variations that can bias the predictions.

Table 3: Optimal models for each sensor depending on the sample and the discrimination method

\begin{tabular}{|l|c|c|c|c|c|c|c|}
\hline \multirow{2}{*}{ Site } & Sensor & Method & Processing & Accuracycal & Accuracy & Qualitative & $\begin{array}{c}\text { Computation } \\
\text { time (s) }\end{array}$ \\
\hline \multirow{4}{*}{ Allos } & VNIR & ANN2 & CLAHE & 0.889 & 0.890 & 3 & 263.840 \\
\cline { 2 - 8 } & SWIR & PLS-DA & SNV & 0.900 & 0.902 & 5 & 0.800 \\
\cline { 2 - 8 } & $\begin{array}{l}\text { VNIR- } \\
\text { SWIR }\end{array}$ & LDA & Raw & 0.931 & 0.935 & 5 & 1.097 \\
\hline \multirow{4}{*}{ Bourget } & VNIR & RF & Raw & 0.996 & 0.995 & 3 & 139.542 \\
\cline { 2 - 8 } & SWIR & PLS-DA & Detrend & 0.969 & 0.958 & 5 & 0.219 \\
\cline { 2 - 8 } & $\begin{array}{l}\text { VNIR- } \\
\text { SWIR }\end{array}$ & PLS-DA & Raw & 0.979 & 0.968 & 4 & 0.276 \\
\hline \multirow{3}{*}{ Geneva } & VNIR & LDA & Detrend & 0.987 & 0.989 & 3 & 1.142 \\
\cline { 2 - 8 } & SWIR & LDA & SNV & 0.992 & 0.989 & 5 & 0.113 \\
\cline { 2 - 8 } & $\begin{array}{l}\text { VNIR- } \\
\text { SWIR }\end{array}$ & LDA & Raw & 0.997 & 0.993 & 4 & 0.437 \\
\hline
\end{tabular}

The classification maps comparison of the optimal and the worst models highlight that the VNIR sensor is more sensitive to surface reliefs, as it can be seen in the Figure 5.a-b with fissures and holes due to sampling, or the Figure 5.d-e with some kind of shadows. One can notice the darker laminated areas on the Bourget and Geneva sediment sections (on the left of the picture) that were not labeled initially because of the non-possibility to precisely label the two classes. In these areas, the VNIR 
sensor predicted most of the pixels in the event layers class might be due to his similar color with this class. In contrast, the SWIR data predict the two groups correctly thanks to the more spectral discriminant information. For the Allos sediment section (Figure 5.a-c), the event layers are easily distinguishable from the continuous sedimentation due to their darker colors. But there is also a color gradient linked to a grain size gradient that is spectrally registered in the SWIR range (Jacq et al., 2019a). That explains the wider layers estimated from the SWIR data than those of the VNIR one, and the lightest layers not visible with the VNIR data.

All these observations and the quantitative validation are agree on the highest discriminant capacities of the SWIR sensor for the separation of event layers from the continuous sedimentation. Thus, the combination of the two sensors is not better, as we could expect due to the VNIR data sensitivity to surface roughness, and they will not be used further on. 
(a) Allos

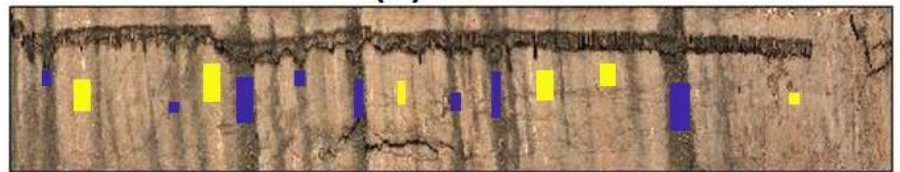

(b) Allos - VNIR- LDA

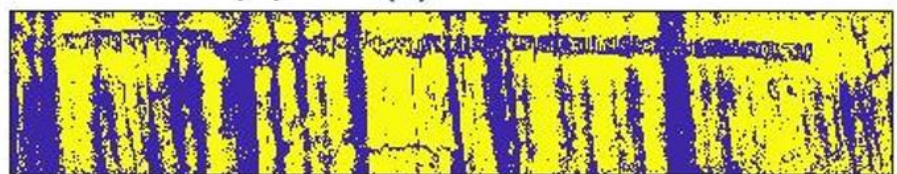

(c) Allos - SWIR- PLS-DA

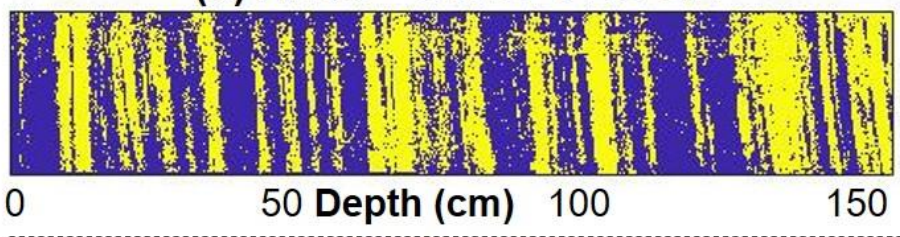

(d) Bourget

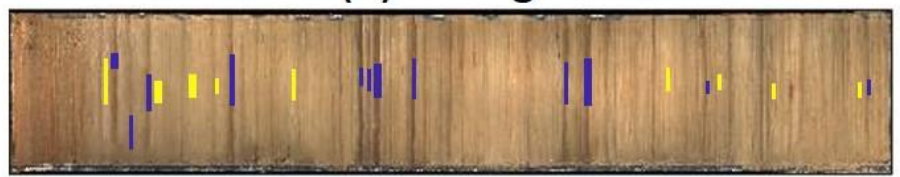

(e) Bourget - VNIR - DT

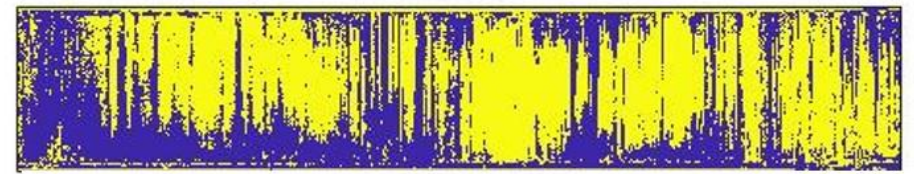

(f) Bourget - SWIR - PLS-DA

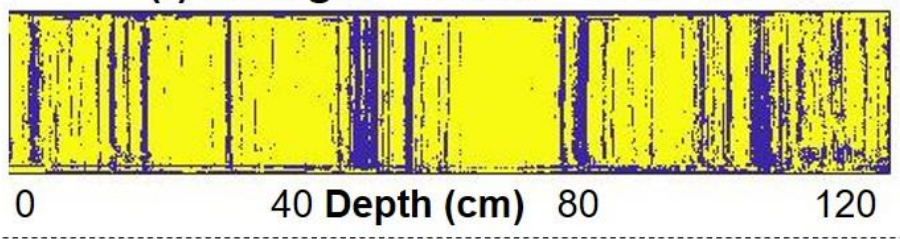

(g) Geneva

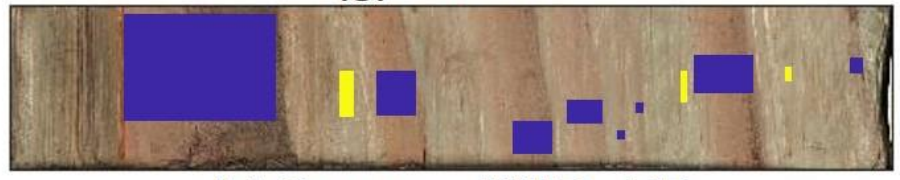

(h) Geneva - VNIR - DT

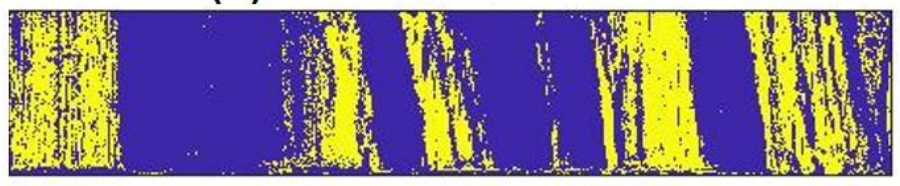

(i) Geneva - SWIR - LDA

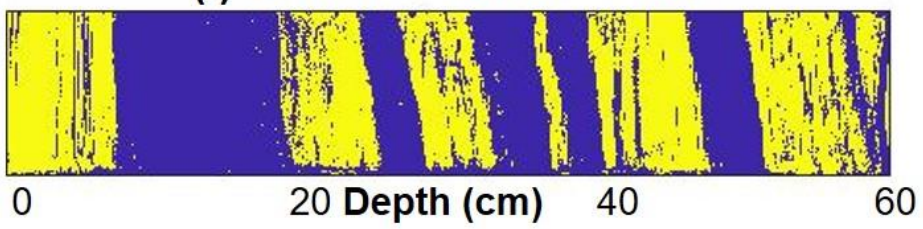

Figure 5: Optimal $(c, f, i)$ and worst $(b, e, h)$ models for each sediment core samples (a, b, c: Allos; $d, e, f:$ Bourget, $h, i, j$ : 


\subsection{Spectral signatures}

The estimation of a SWIR wavelength cumulative occurrence allows to find the discriminant ones and to characterize them (Figure 6). Five discriminant spectral areas present high cumulative values and can be associated with chemical properties (Viscarra Rossel and Behrens, 2010). Organic components can be related to the spectral wavelengths between (1) $1100-1200 \mathrm{~nm}$ and (2) $1650-1750 \mathrm{~nm}$. The three others correspond to spectral ranges with possible overlaps: (3) organic compounds and hydroxyl bonds (moisture, organic matter or mineral) between 1400-1500 nm and 1800-1950 nm, (4) mineral (clay), and organic compounds between $2180-2300 \mathrm{~nm}$.
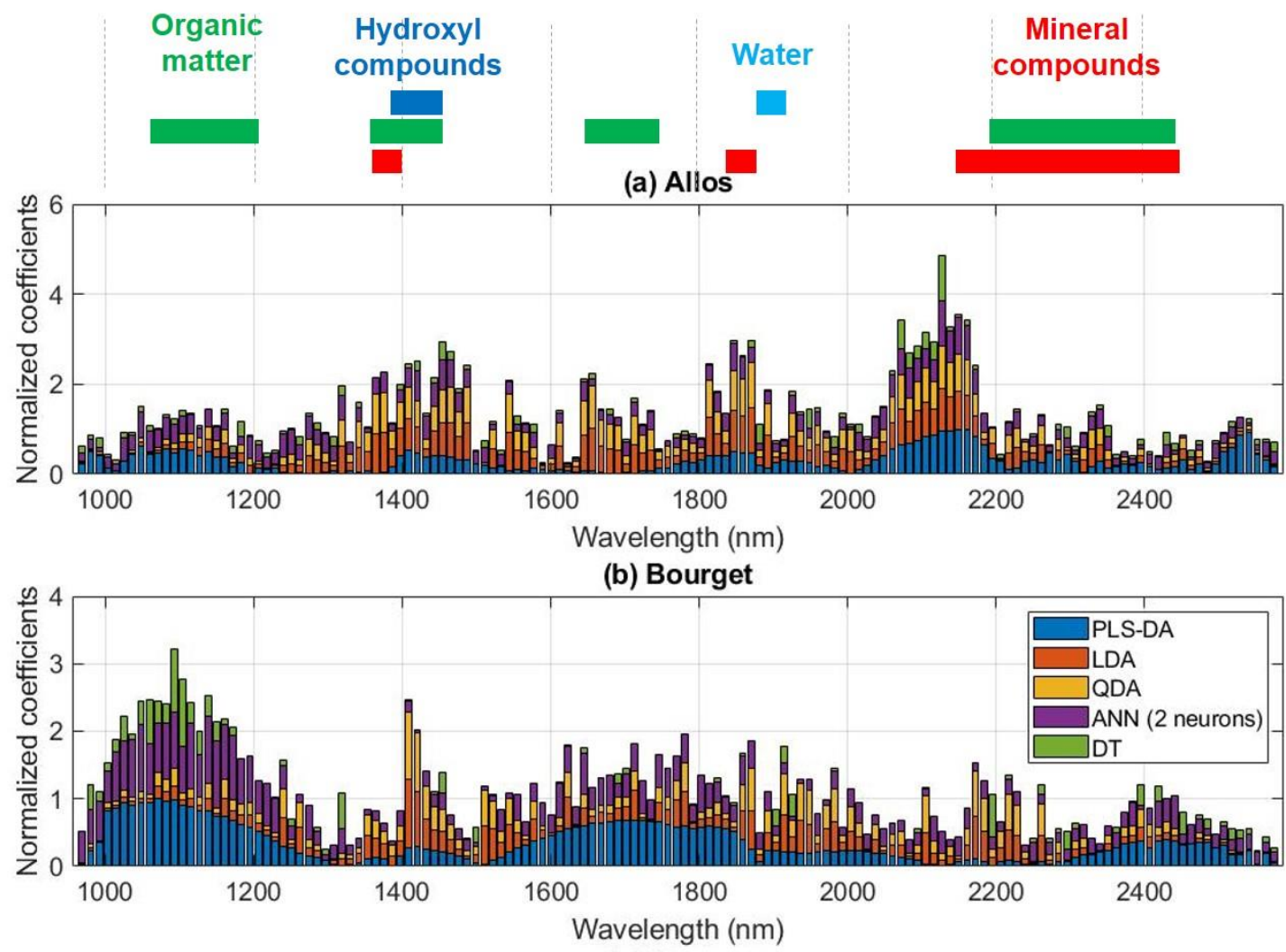

(c) Geneva

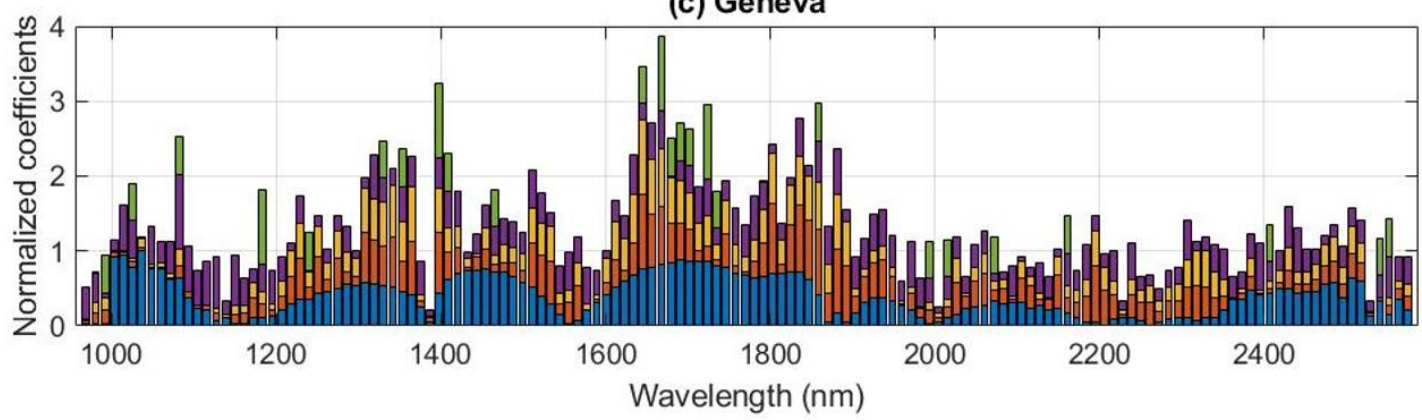


Figure 6: Comparison of the normalized coefficients (coefficient weights normalized to one for each method) used by the optimal SWIR models to highlight the discriminant wavelengths: (a) Allos, 'b) Bourget, (c) Geneva samples.

The three optimal models use similar discriminant wavelengths but with different importance depending on the sediment properties. The two hydroxyl bonds spectral areas have important implications in the three models that can be associated with the moisture and the particle size. Otherwise, the two classes seem to be discriminated by the mineralogy for the Allos sediment sequence, the organic matter for the Bourget and Geneva sequences.

\section{Discussion}

\subsection{Model transfer}

The optimal SWIR models developed on each core were used to estimate the classification maps of the other ones to see the capability of the model transfer. Table 4 shows the results of these classifications with the test accuracies and qualitative indicators. Most of them agree on the difficulty of transferring the model to other cores. Only the model developed with the Bourget data has some capacity to predict on the other, maybe due to its discriminant wavelengths that are less spectrally localized than the two other models (Allos: $2100-2200 \mathrm{~nm}$, Geneva: $1650-1700 \mathrm{~nm}$ ).

Table 4: Comparison of site-specific models for the transferability on the other cores

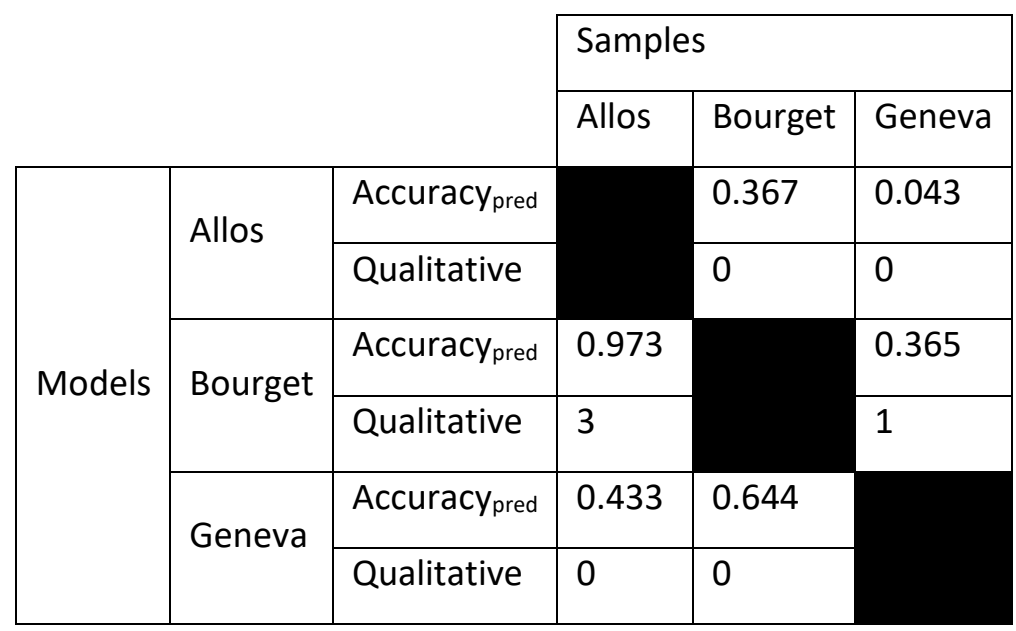


Based on these results, the estimation of a classification model is sample-specific. It can be made with a linear discriminant method as LDA or PLS-DA with the raw SWIR dataset, even if some pretreatment can slightly improve the performance.

\subsection{Event layer classification with classical images}

The true-RGB image can also be converted into HSV (Hue, Saturation, Lightness) or L*a*b* (lightness, color) color spaces, and reduce in grayscale level. The HSV and L*a*b* transformations have proved to be more adapted for classification purposes (Bora et al., 2015; Hernández-Hernández et al., 2016). The grayscale levels are the most straightforward color space.

Table 5 shows that the conventional image presents slightly lower performances as VNIR and also the same mispredictions with surface variations, shadows, and laminated areas (Supplementary figure 2). All these observations highlight that these methods learn too much the color of the deposits with VNIR data and do not learn sufficiently from the chemical composition, contrary to SWIR HSI. Then, machine learning and conventional image can be used in the case of a clean image and sample, with only color differences between the classes and the learning of all kinds of sample events and defects.

Table 5: Comparison of the conventional image discriminant models with the optimal estimated with the hyperspectral

$$
\text { images }
$$

\begin{tabular}{|c|c|c|c|c|c|c|c|}
\hline Sample & Performances & Grayscale & RGB & HSV & $L * a * b *$ & $\begin{array}{l}\text { VNIR } \\
\text { HSI }\end{array}$ & $\begin{array}{l}\text { SWIR } \\
\text { HSI }\end{array}$ \\
\hline \multirow{4}{*}{ Allos } & Method & \multicolumn{5}{|c|}{ ANN - 2 neurons } & PLS-DA \\
\hline & Accuracycal & 0.966 & 0.821 & 0.817 & 0.821 & 0.889 & 0.900 \\
\hline & Accuracypred & 0.963 & 0.824 & 0.808 & 0.823 & 0.890 & 0.902 \\
\hline & Qualitative & 4 & 4 & 4 & 4 & 3 & 5 \\
\hline \multirow{4}{*}{ Bourget } & Method & \multicolumn{4}{|c|}{ ANN - 2 neurons } & RF & PLS-DA \\
\hline & Accuracy $_{\text {cal }}$ & 0.995 & 0.903 & 0.904 & 0.906 & 0.996 & 0.969 \\
\hline & Accuracypred & 0.994 & 0.898 & 0.899 & 0.903 & 0.995 & 0.958 \\
\hline & Qualitative & 2 & 2 & 2 & 2 & 3 & 5 \\
\hline Geneva & Method & \multicolumn{4}{|c|}{ ANN -2 neurons } & LDA & LDA \\
\hline
\end{tabular}




\begin{tabular}{|l|l|l|l|l|l|l|l|}
\hline & Accuracy & 0.911 & 0.976 & 0.976 & 0.975 & 0.987 & 0.992 \\
\cline { 2 - 8 } & Accuracy & & & & & & \\
& 0.884 & 0.979 & 0.983 & 0.982 & 0.989 & 0.989 \\
\cline { 2 - 8 } & Qualitative & 1 & 2 & 2 & 2 & 4 & 5 \\
\hline
\end{tabular}

\subsection{Comparison between an HSI and a naked-eye chronicles}

The discretization of the event layer allows to estimate their occurrence along the sediment section and to compare it with the naked-eye event chronicle. The classification map was reduced to a summed profile, with pixels equal to 0 for continuous sedimentation and 1 for an event layer. This assumes that deposits are parallel, if this is not the case, image processing needs to be used to correct the deformation when possible. This profile can also be used as an event occurrence probability with the normalization by the pixel number of the image width. It was smoothed with a second-order polynomial Savitzky-Golay filter to reduce miss-classifications (Savitzky and Golay, 1964). A low threshold (lower than 20\%) allows to separate all the deposits, but also find some artifacts, and the boundaries can be overestimated due to curvatures. Conversely, a high threshold (higher than 70\%) only finds the large deposits, but close ones can be fused. Thus, a double threshold was used. First, to the half-width of the image to classify each column to one class, it allowed to find most of the relevant deposits, but close layers can be seen as a large one. The second threshold of $15 \%$ of the image width was used for event layers thicker than $5 \mathrm{~mm}$ to divide them potentially. Finally, the chronicle can be reconstructed with the depth and thickness of each event layer. Naked eye chronicles of the three cores were estimated and can be compared with those from hyperspectral (Jenny et al., 2014b; Wilhelm et al., 2012).

Figure 7 compares the identification of event layers in depths and thickness between HSI and nakedeye approaches. In general, HSI results in thicker event layers compared to naked-eye observations. This can be explained by the eye limitation to characterize the event limits (resolution grain) or by the curvature of it (miss-identification). Machine learning also allows to identify new deposits that were not visually detected (due to their small thickness or texture or color differences). They must be assessed by other high-resolution technics as microscopy to verify their relevancies. The number of 
detected event layers is higher (Table 1, Table 6) due to the detection of supplementary thinner layers.

Initially, this work was developed to study only flood events that were manually labeled. Still, HSI does not seem to have enough discriminant spectral information to distinguish the different triggering mechanisms of the event layers (e.g., flood, slumps induced by seismic-shaking...). However, the HSI model corresponds to the first fast and non-destructive method to detect, in a semi-automatic way, event layers in different sedimentary contexts and represent a clear improvement in sedimentology.

(a)

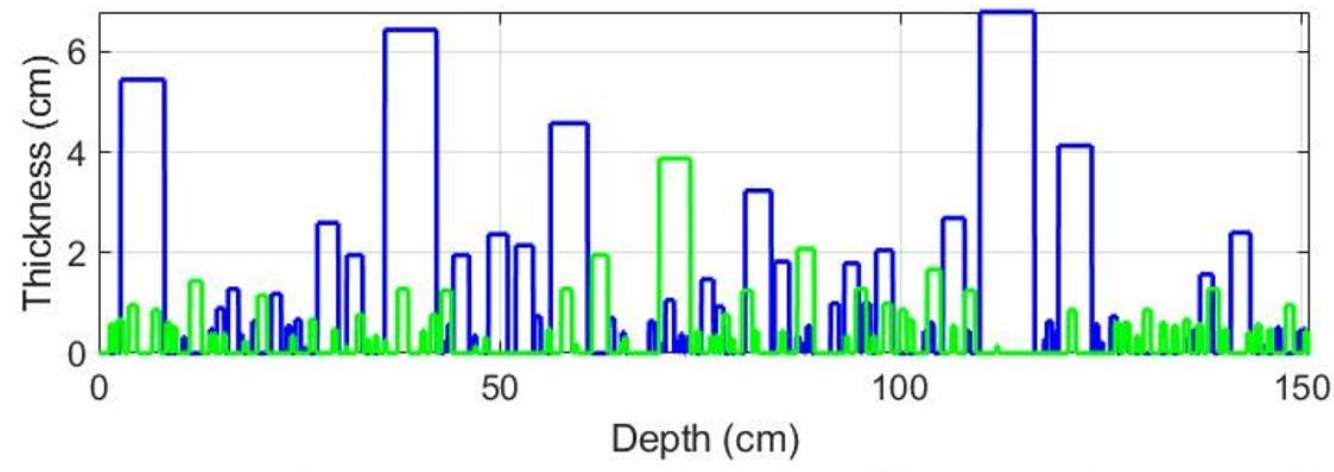

(b)

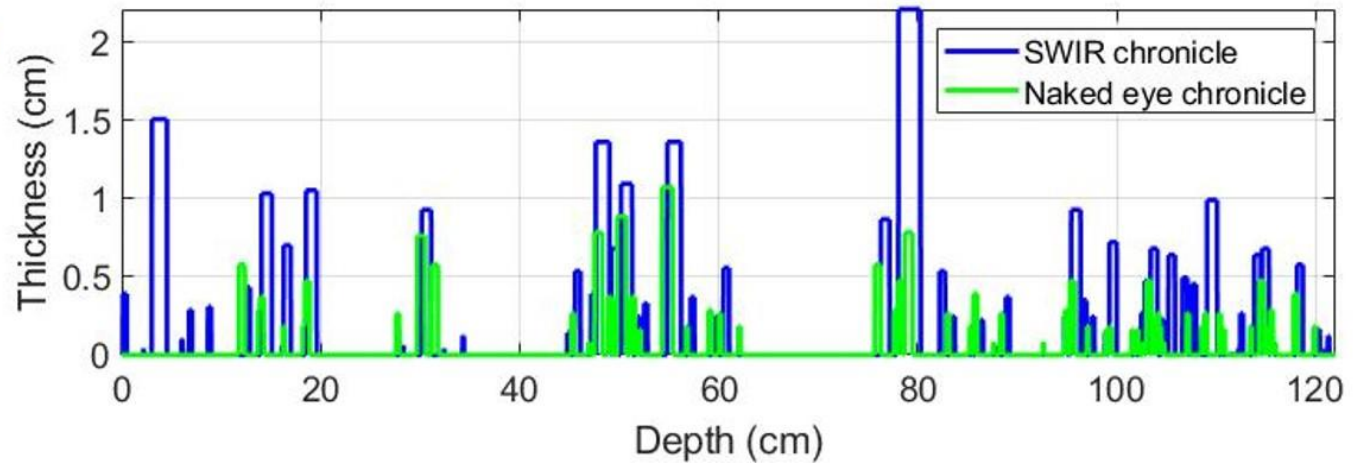

(c)

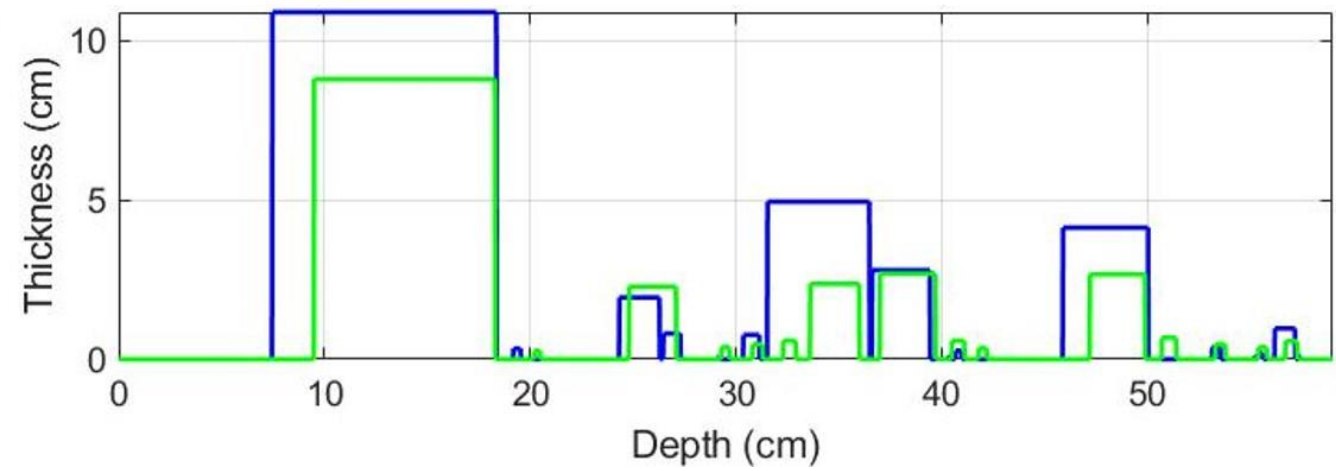

Figure 7: Comparison of the naked-eye and HSI estimated chronicles for the three samples: (a) Allos, (b) Bourget, (c) Geneva 
Table 6: Statistics of the HSI event layer detections

\begin{tabular}{|l|l|l|l|l|l|l|}
\cline { 2 - 7 } \multicolumn{1}{c|}{} & $\mathrm{N}$ & $\mathrm{N}_{<1 \mathrm{~mm}}$ & $\begin{array}{l}\text { Average } \\
(\mathrm{mm})\end{array}$ & $\begin{array}{l}\text { Standard deviation } \\
(\mathrm{mm})\end{array}$ & $\begin{array}{l}\text { Minimum } \\
(\mathrm{mm})\end{array}$ & $\begin{array}{l}\text { Maximum } \\
(\mathrm{mm})\end{array}$ \\
\hline Allos & 88 & 12 & 9.64 & 13.51 & 0.32 & 68.19 \\
\hline Bourget & 72 & 19 & 4.24 & 4.28 & 0.20 & 22.31 \\
\hline Geneva & 26 & 11 & 11.37 & 23.81 & 0.22 & 109.01 \\
\hline
\end{tabular}

\subsection{Perspectives}

It is worth noting that we focus only on event layers and that models are site-specific. Some strategies can be tested on future works. The first one is to create a multi-site database to learn several event types and continuous sedimentation cases (strata or homogeneous). A second could be to use complementary information estimated by other sensors, for example, XRF spectroscopy for elemental composition, which is also a non-destructive, high-resolution (up to $200 \mu \mathrm{m}$ ) analysis. It will also be interesting using a spatial-spectral approach to add information contained in both dimensions, like color and grain size gradient, along with a flood event. Deep learning with the convolutional neural network (CNN) use this kind of approach and can be interesting for a multi-site and a large database. This method introduces multiscale local features learning and some translation and rotation invariance, which is of interest for image classification (Schmidhuber, 2015). We have tested a CNN1D, that uses only the spectral dimension, but it presents low performances that may be due to a too-small database and to a too simple problem that an ANN with few neurons can model. In future work, we will use a CNN3D, that use a spatial-spectral approach (Ben Hamida et al., 2018). We have shown previously that the combination of VNIR and SWIR does not increase the discriminating capacity. Improvements can be made with surface defect correction before the acquisition or after with pre-processing, or detected and removed them from the classification map. Another way could be to make two separate classifications with both sensors and then to combine them with different weights using e.g., fuzzy or belief functions methods to improve the certainty of the predictions (Lian et al., 2019; Tehrani et al., 2019). 
This study has shown that event layers can be estimated at high-resolution with hyperspectral imaging for the cores used in calibration. A first discriminant model, based on LDA or PLS-DA, estimated with the raw hyperspectral data can allows to know the possibility of discrimination between different classes. A similar method has already been used for the detection of tephra layers (Aymerich et al., 2016). So, the proposed method may be used for a case study for other types of events, like tsunamis, earthquakes, landslides, storms, or any other laminae. It can be very useful for paleoenvironment and paleoclimate studies and will allow the creation of event chronicles.

\section{Conclusions}

We studied the potential of three hyperspectral sensors (VNIR, SWIR, VNIR-SWIR) to image three sediment cores and created machine learning models. The aim is to automatically discriminate different types of sedimentation (continuous versus event layer) with non-destructive, highresolution, and time-saving methods. Seven discrimination methods, coupled with raw data or eight pre-processing, were used to find an optimal model. We found that the SWIR sensor allows creating the most robust models with discriminant analysis (LDA, PLS-DA). Raw data presents relevant predictions, but the use of a pre-processing can slightly improve the performances and robustness. The models were assessed quantitatively with prediction accuracies higher than 0.9. For the qualitative one, event layers present colors and textures that differ from the continuous sedimentation and can be seen with a naked-eye observation to check the relevance of the prediction maps. The discriminant wavelengths are associated with organic matters and some mineral bands. Finally, the event chronicles can be estimated from the classification maps with the estimation of the depth and thicknesses of each deposit. Unfortunately, the hyperspectral sensors used in this study do not have enough spectral discriminant information to characterize the trigger of the event layer and if different types of events exist. Future works will allow to characterize triggers by the combination of hyperspectral imaging with other sensors or by the use of spatial-spectral machine learning methods. This study highlights the sediment lithologies discrimination capacity of 
hyperspectral imaging with manual labeling. The application of this method on sediment sections will allow to create robust chronicles of events with characteristic wavelengths and thus, enhance the knowledge of the evolution of the frequency of extreme geodynamical events.

\section{Acknowledgements}

Coring supports were provided by the French National Research Agency's with the IPER-RETRO program for lake Geneva (ANR-08-VUL 005), the Pygmalion project for lake Allos (ANR BLAN072_204489). Hyperspectral imaging was processed at the University of Normandie-Rouen and was funded by the Region Normandie, which supports the scientific consortium SCALE UMR CNRS 3730. 


\section{References}

Aymerich, I.F., Oliva, M., Giralt, S., Martín-Herrero, J., 2016. Detection of Tephra Layers in Antarctic Sediment Cores with Hyperspectral Imaging. PLoS One 11, 1-24.

https://doi.org/10.1371/journal.pone.0146578

Barnes, R.J., Dhanoa, M.S., Lister, S.J., 1989. Standard Normal Variate Transformation and DeTrending of Near-Infrared Diffuse Reflectance Spectra. Appl. Spectrosc. 43, 772-777. https://doi.org/10.1366/0003702894202201

Ben Hamida, A., Benoit, A., Lambert, P., Ben Amar, C., 2018. 3-D Deep Learning Approach for Remote Sensing Image Classification. IEEE Trans. Geosci. Remote Sens. 56, 4420-4434. https://doi.org/10.1109/TGRS.2018.2818945

Bora, D.J., Gupta, A.K., Khan, F.A., 2015. Comparing the Performance of L*A*B* and HSV Color Spaces with Respect to Color Image Segmentation. Int. J. Emerg. Technol. Adv. Eng. 5, 192-203.

Breiman, L., Friedman, J.H., Olshen, R.A., Stone, C.J., 1984. Classification And Regression Trees. Routledge. https://doi.org/10.1201/9781315139470

Bull, C.R., 1991. Wavelength selection for near-infrared reflectance moisture meters. J. Agric. Eng. Res. 49, 113-125. https://doi.org/10.1016/0021-8634(91)80032-A

Butz, C., Grosjean, M., Fischer, D., Wunderle, S., Tylmann, W., Rein, B., 2015. Hyperspectral imaging spectroscopy: a promising method for the biogeochemical analysis of lake sediments. J. Appl. Remote Sens. 9, 1-20. https://doi.org/10.1117/1.JRS.9.096031

Butz, C., Grosjean, M., Goslar, T., Tylmann, W., 2017. Hyperspectral imaging of sedimentary bacterial pigments: a 1700-year history of meromixis from varved Lake Jaczno, northeast Poland. J. Paleolimnol. 1-16. https://doi.org/10.1007/s10933-017-9955-1

Chagué-Goff, C., 2010. Chemical signatures of palaeotsunamis: A forgotten proxy? Mar. Geol. 271, 
67-71. https://doi.org/10.1016/j.margeo.2010.01.010

CIE, 1999. IEC 61966-2-1:1999: Multimedia systems and equipment - Colour measurement and management - Part 2-1: Colour management - Default RGB colour space - sRGB.

Ebert, T., Trauth, M.H., 2015. Semi-automated detection of annual laminae (varves) in lake sediments using a fuzzy logic algorithm. Palaeogeogr. Palaeoclimatol. Palaeoecol. 435, 272-282. https://doi.org/10.1016/j.palaeo.2015.05.024

Feng, J., Rogge, D., Rivard, B., 2018. Comparison of lithological mapping results from airborne hyperspectral VNIR-SWIR, LWIR and combined data. Int. J. Appl. Earth Obs. Geoinf. 64, 340353. https://doi.org/10.1016/J.JAG.2017.03.003

Fisher, R.A., 1936. The Use of Multiple Measurements in Taxonomic Problems. Ann. Eugen. 7, 179188. https://doi.org/10.1111/j.1469-1809.1936.tb02137.x

Fouinat, L., Sabatier, P., Poulenard, J., Reyss, J.-L., Montet, X., Arnaud, F., 2017. A new CT scan methodology to characterize a small aggregation gravel clast contained in a soft sediment matrix. Earth Surf. Dyn. 5, 199-209. https://doi.org/10.5194/esurf-5-199-2017

Gaume, E., Bain, V., Bernardara, P., Newinger, O., Barbuc, M., Bateman, A., Blaškovičová, L., Blöschl, G., Borga, M., Dumitrescu, A., Daliakopoulos, I., Garcia, J., Irimescu, A., Kohnova, S., Koutroulis, A., Marchi, L., Matreata, S., Medina, V., Preciso, E., Sempere-Torres, D., Stancalie, G., Szolgay, J., Tsanis, I., Velasco, D., Viglione, A., 2009. A compilation of data on European flash floods. J. Hydrol. 367, 70-78. https://doi.org/10.1016/J.JHYDROL.2008.12.028

Gilli, A., Anselmetti, F.S., Glur, L., Wirth, S.B., 2013. Lake Sediments as Archives of Recurrence Rates and Intensities of Past Flood Events, in: Dating Torrential Processes on Fans and Cones: Methods and Their Application for Hazard and Risk Assessment. pp. 225-242. https://doi.org/10.1007/978-94-007-4336-6_15

Glur, L., Wirth, S.B., Büntgen, U., Gilli, A., Haug, G.H., Schär, C., Beer, J., Anselmetti, F.S., 2013. 
Frequent floods in the European Alps coincide with cooler periods of the past 2500 years. Sci. Rep. 3, 2770. https://doi.org/10.1038/srep02770

Hernández-Hernández, J.L., García-Mateos, G., González-Esquiva, J.M., Escarabajal-Henarejos, D., Ruiz-Canales, A., Molina-Martínez, J.M., 2016. Optimal color space selection method for plant/soil segmentation in agriculture. Comput. Electron. Agric. 122, 124-132. https://doi.org/10.1016/J.COMPAG.2016.01.020

Ho, T.K., 1995. Random decision forests, in: Proceedings of 3rd International Conference on Document Analysis and Recognition. IEEE Comput. Soc. Press, pp. 278-282. https://doi.org/10.1109/ICDAR.1995.598994

Ivakhnenko, A., Lapa, V.G., 1965. Cybernetic predicting devices. CCM Information Corp., New York. Jacq, K., Giguet-Covex, C., Sabatier, P., Perrette, Y., Fanget, B., Coquin, D., Debret, M., Arnaud, F., 2019a. High-resolution grain size distribution of sediment core with hyperspectral imaging. Sediment. Geol. 393-394. https://doi.org/10.1016/j.sedgeo.2019.105536

Jacq, K., Perrette, Y., Fanget, B., Sabatier, P., Coquin, D., Debret, M., Arnaud, F., 2019b. Laboratory hyperspectral imaging a powerful tool for a fast-high-resolution analysis of natural sample: application to sediment core, in: European Geosciences Union (EGU).

Jacq, K., Perrette, Y., Fanget, B., Sabatier, P., Coquin, D., Martinez-Lamas, R., Debret, M., Arnaud, F., 2019c. High-resolution prediction of organic matter concentration with hyperspectral imaging on a sediment core. Sci. Total Environ. 663, 236-244. https://doi.org/10.1016/j.scitotenv.2019.01.320

Jenny, J.-P., Arnaud, F., Alric, B., Dorioz, J.-M., Sabatier, P., Meybeck, M., Perga, M.-E., 2014a. Inherited hypoxia: A new challenge for reoligotrophicated lakes under global warming. Global Biogeochem. Cycles 28, 1413-1423. https://doi.org/10.1002/2014GB004932

Jenny, J.-P., Wilhelm, B., Arnaud, F., Sabatier, P., Giguet Covex, C., Mélo, A., Fanget, B., Malet, E., 
Ployon, E., Perga, M.E., 2014b. A 4D sedimentological approach to reconstructing the flood frequency and intensity of the Rhône River (Lake Bourget, NW European Alps). J. Paleolimnol. 51, 469-483. https://doi.org/10.1007/s10933-014-9768-4

Lian, C., Ruan, S., Denoeux, T., Li, H., Vera, P., 2019. Joint Tumor Segmentation in PET-CT Images Using Co-Clustering and Fusion Based on Belief Functions. IEEE Trans. Image Process. 28, 755766. https://doi.org/10.1109/TIP.2018.2872908

Liu, C., Yuen, J., Torralba, A., 2011. SIFT Flow: Dense Correspondence across Scenes and Its Applications. IEEE Trans. Pattern Anal. Mach. Intell. 33, 978-994. https://doi.org/10.1109/TPAMI.2010.147

Lorenz, S., Seidel, P., Ghamisi, P., Zimmermann, R., Tusa, L., Khodadadzadeh, M., Contreras, I.C., Gloaguen, R., 2019. Multi-Sensor Spectral Imaging of Geological Samples: A Data Fusion Approach Using Spatio-Spectral Feature Extraction. Sensors 19, 2787. https://doi.org/10.3390/s19122787

Lotter, andré f., Lemcke, G., 1999. Methods for preparing and counting biochemical varves. Boreas 28, 243-252. https://doi.org/10.1111/j.1502-3885.1999.tb00218.x

Makri, S., Rey, F., Gobet, E., Gilli, A., Tinner, W., Grosjean, M., 2020. Early human impact in a 15,000year high-resolution hyperspectral imaging record of paleoproduction and anoxia from a varved lake in Switzerland. Quat. Sci. Rev. 239, 1-14. https://doi.org/10.1016/j.quascirev.2020.106335

McCulloch, W.S., Pitts, W., 1943. A logical calculus of the ideas immanent in nervous activity. Bull. Math. Biophys. 5, 115-133. https://doi.org/10.1007/BF02478259

Meyer, M.C., Faber, R., Spö TI, C., 2006. The WinGeol Lamination Tool : new software for rapid, semi - automated analysis of laminated climate archives. The Holocene 16, 753-761. https://doi.org/10.1191/0959683606hl969rr 
Sediments Analysis. Int. J. Geosci. 3, 206-210. https://doi.org/10.4236/ijg.2012.31023

Pearson, K., 1901. On lines and planes of closest fit to systems of points in space. Philos. Mag. 2, 559572. https://doi.org/10.1080/14786440109462720

Rinnan, Å., Berg, F. van den, Engelsen, S.B., 2009. Review of the most common pre-processing techniques for near-infrared spectra. TrAC Trends Anal. Chem. 28, 1201-1222. https://doi.org/10.1016/J.TRAC.2009.07.007

Rosenblatt, F., 1958. The Perceptron: A Probabilistic Model for Information Storage and Organization in The Brain. Psychol. Rev. 65, 386-408.

Sabatier, P., Dezileau, L., Colin, C., Briqueu, L., Bouchette, F., Martinez, P., Siani, G., Raynal, O., Von Grafenstein, U., 2012. 7000 years of paleostorm activity in the NW Mediterranean Sea in response to Holocene climate events. Quat. Res. 77, 1-11. https://doi.org/10.1016/j.yqres.2011.09.002

Savitzky, A., Golay, M.J.E., 1964. Smoothing and Differentiation of Data by Simplified Least Squares Procedures. Anal. Chem. 36, 1627-1639. https://doi.org/10.1021/ac60214a047

Schmidhuber, J., 2015. Deep Learning in Neural Networks: An Overview. Neural Networks 61, 85117. https://doi.org/10.1016/j.neunet.2014.09.003

Schneider, T., Rimer, D., Butz, C., Grosjean, M., 2018. A high-resolution pigment and productivity record from the varved Ponte Tresa basin (Lake Lugano, Switzerland) since 1919: insight from an approach that combines hyperspectral imaging and high-performance liquid chromatography. J. Paleolimnol. 1-18. https://doi.org/10.1007/s10933-018-0028-x

Tehrani, A.K.N., Macktoobian, M., Kasaei, S., 2019. Color Image Segmentation Using a Fuzzy Inference System, in: Proceedings - 2019 7th International Conference on Digital Information Processing and Communications, ICDIPC 2019. Institute of Electrical and Electronics Engineers Inc., pp. 78-83. https://doi.org/10.1109/ICDIPC.2019.8723780 
Tusa, L., Khodadadzadeh, M., Contreras, C., Shahi, K.R., Fuchs, M., Gloaguen, R., Gutzmer, J., 2020. Drill-Core Mineral Abundance Estimation Using Hyperspectral and High-Resolution Mineralogical Data. Remote Sens. 12. https://doi.org/10.3390/rs12071218

Van Exem, A., Debret, M., Copard, Y., Verpoorter, C., De Wet, G., Lecoq, N., Sorrel, P., Werner, A., Roof, S., Laignel, B., Retelle, M., 2019. New source-to-sink approach in an arctic catchment based on hyperspectral core-logging (Lake Linné, Svalbard). Quat. Sci. Rev. 203, 128-140. https://doi.org/10.1016/J.QUASCIREV.2018.10.038

Vannière, B., Magny, M., Joannin, S., Simonneau, A., Wirth, S.B., Hamann, Y., Chapron, E., Gilli, A., Desmet, M., Anselmetti, F.S., 2013. Orbital changes, variation in solar activity and increased anthropogenic activities: controls on the Holocene flood frequency in the Lake Ledro area, Northern Italy. Clim. Past 9, 1193-1209. https://doi.org/10.5194/cp-9-1193-2013

Vidal, M., Amigo, J.M., 2012. Pre-processing of hyperspectral images. Essential steps before image analysis. Chemom. Intell. Lab. Syst. 117, 138-148. https://doi.org/10.1016/J.CHEMOLAB.2012.05.009

Viscarra Rossel, R.A., Behrens, T., 2010. Using data mining to model and interpret soil diffuse reflectance spectra. Geoderma 158, 46-54. https://doi.org/10.1016/j.geoderma.2009.12.025

Weber, M.E., Reichelt, L., Kuhn, G., Pfeiffer, M., Korff, B., Thurow, J., Ricken, W., 2010. BMPix and PEAK tools: New methods for automated laminae recognition and counting-Application to glacial varves from Antarctic marine sediment. Geochemistry, Geophys. Geosystems 11. https://doi.org/10.1029/2009GC002611

Wilhelm, B., Arnaud, F., Sabatier, P., Crouzet, C., Brisset, E., Chaumillon, E., Disnar, J.-R., Guiter, F., Malet, E., Reyss, J.-L., Tachikawa, K., Bard, E., Delannoy, J.-J., 2012. 1400 years of extreme precipitation patterns over the Mediterranean French Alps and possible forcing mechanisms. Quat. Res. 78, 1-12. https://doi.org/10.1016/J.YQRES.2012.03.003 
Wilhelm, B., Ballesteros Canovas, J.A., Corella Aznar, J.P., Kämpf, L., Swierczynski, T., Stoffel, M., Støren, E., Toonen, W., 2018. Recent advances in paleoflood hydrology: From new archives to data compilation and analysis. Water Secur. 3, 1-8.

https://doi.org/10.1016/j.wasec.2018.07.001

Wilhelm, B., Nomade, J., Crouzet, C., Litty, C., Sabatier, P., Belle, S., Rolland, Y., Revel, M., Courboulex, F., Arnaud, F., Anselmetti, F.S., 2016. Quantified sensitivity of small lake sediments to record historic earthquakes: Implications for paleoseismology. J. Geophys. Res. Earth Surf. 121, 2-16. https://doi.org/10.1002/2015JF003644

Wilhelm, B., Sabatier, P., Arnaud, F., 2015. Is a regional flood signal reproducible from lake sediments? Sedimentology 62, 1103-1117. https://doi.org/10.1111/sed.12180

Wold, S., Ruhe, A., Wold, H., Dunn, III, W.J., 1984. The Collinearity Problem in Linear Regression. The Partial Least Squares (PLS) Approach to Generalized Inverses. SIAM J. Sci. Stat. Comput. 5, 735743. https://doi.org/10.1137/0905052

Zuiderveld, K., 1994. Contrast Limited Adaptive Histogram Equalization, in: Graphics Gems IV. Academic Press, pp. 474-485. https://doi.org/10.1016/B978-0-12-336156-1.50061-6 


\section{Supplementary}

\subsection{Figure}

(a) Allos

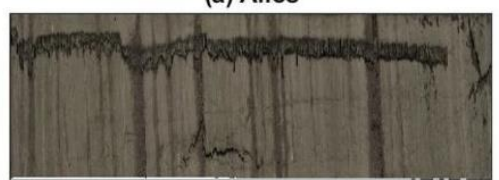

(d) Allos(Allos)

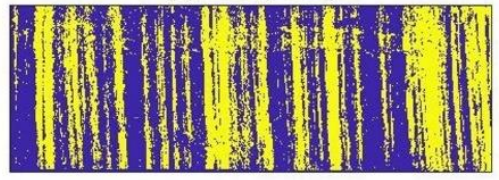

(g) Bourget(Allos)

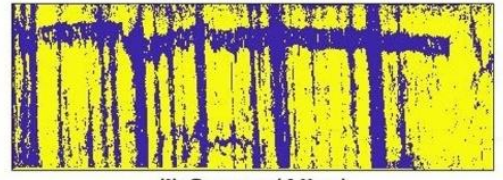

(j) Geneva(Allos)

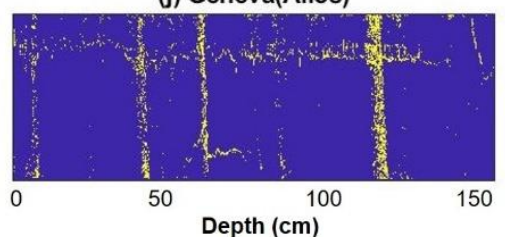

(b) Bourget

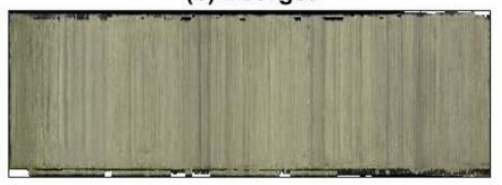

(e) Allos(Bourget)

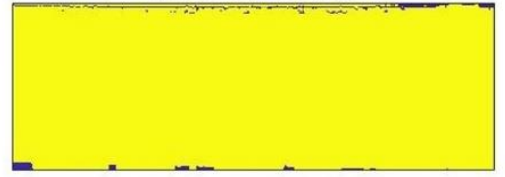

(h) Bourget(Bourget)

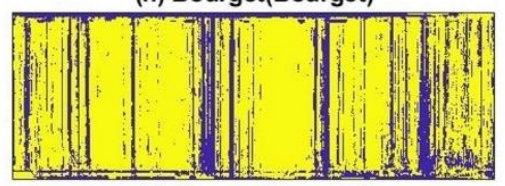

(k) Geneva(Bourget)

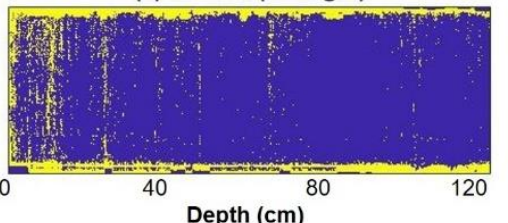

(c) Geneva

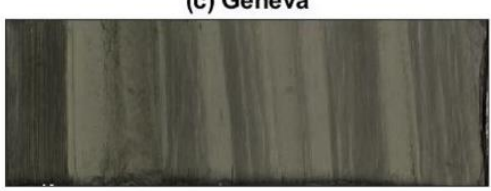

(f) Allos(Geneva)

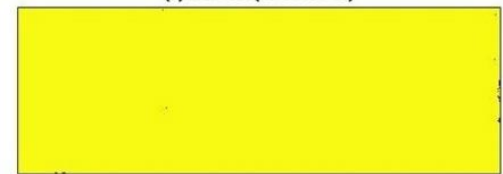

(i) Bourget(Geneva)

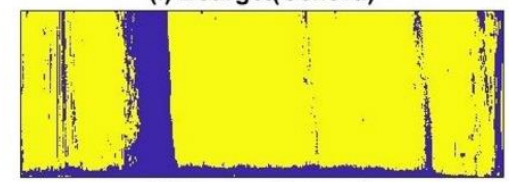

(I) Geneva(Geneva)

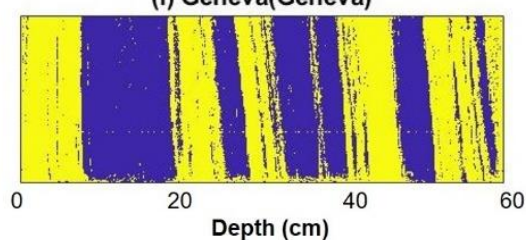

Supplementary figure 1: Classification maps estimated by model transfer, (d-e-f): Allos model, (g-h-i): Bourget model, (j-k-l): Geneva model; (d-g-j): Allos data, (e-h-k): Bourget data, (f-i-l): Geneva data. 
(a) Allos

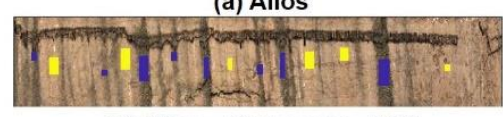

(b) Allos - Grayscale - ANN

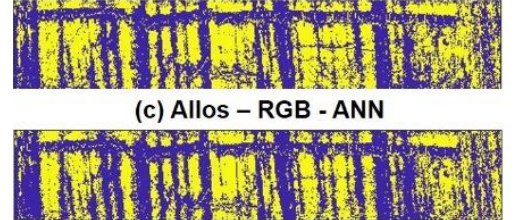

(d) Allos - HSV - ANN

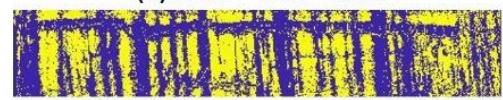

(e) Allos - Lab - ANN

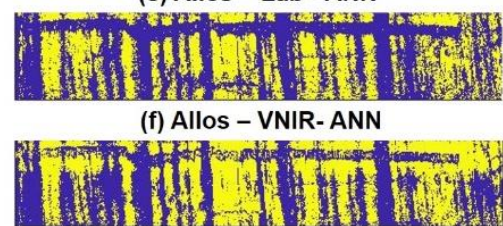

(g) Allos - SWIR- PLS-DA

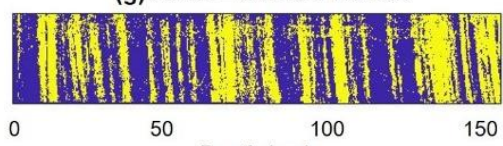

(h) Bourget

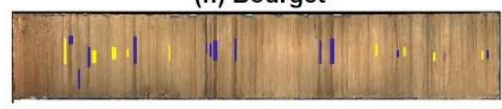

(i) Bourget - Grayscale - ANN

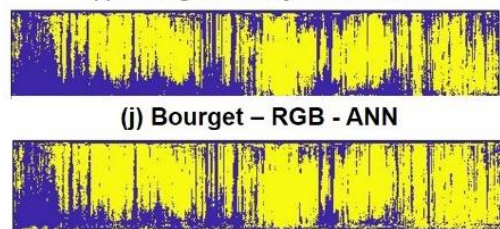

(k) Bourget - HSV - ANN

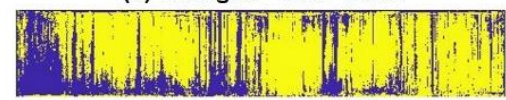

(I) Bourget - Lab - ANN

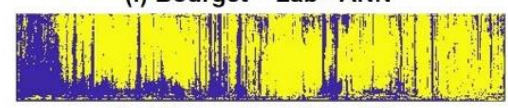

(m) Bourget - VNIR - RF

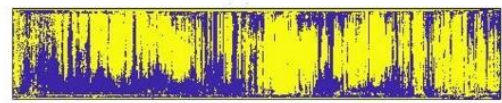

(n) Bourget - SWIR - PLS-DA

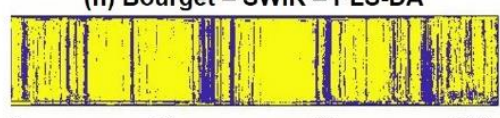

40 (o) Geneva

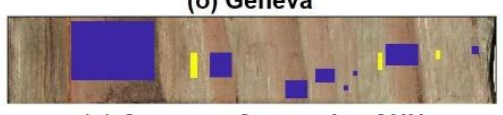

(p) Geneva - Grayscale - ANN

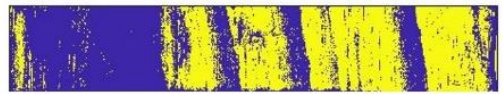

(q) Geneva - RGB - ANN

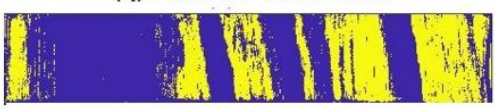

(r) Geneva - HSV - ANN

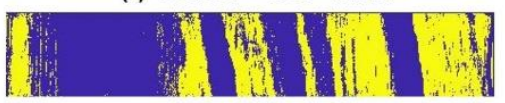

(s) Geneva - Lab - ANN

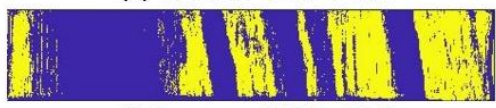

(t) Geneva - VNIR - LDA

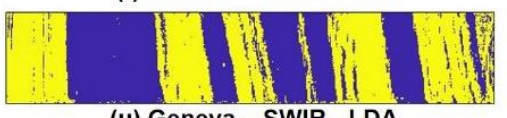

(u) Geneva - SWIR - LDA

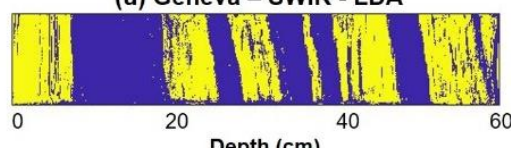

Supplementary figure 2: Comparison of the classification maps estimated by the learning of the conventional images and HSI

\subsection{Table}

Supplementary table 1: Parameters of each machine learning method

\begin{tabular}{|l|l|}
\hline Method & Parameters \\
\hline DT & $\begin{array}{l}\text { Split predictor: Standard CART } \\
\text { Split criterion: Gini's diversity index } \\
\text { Decision tree pruning based on error criterion }\end{array}$ \\
\hline RF & $\begin{array}{l}\text { Ensemble-aggregation method: Adaptive logistic regression } \\
\text { Number of ensemble learning cycles: } 100\end{array}$ \\
\hline ANN & $\begin{array}{l}\text { Number of neurons: } 2-10 \\
\text { Training function: Scaled conjugate gradient backpropagation } \\
\text { Performance function: Cross-Entropy }\end{array}$ \\
\hline LDA & Discriminant type: Linear \\
\hline QDA & Discriminant type: Quadratic \\
\hline PLS-DA & $\begin{array}{l}\text { Latent variable estimation method: NIPALS } \\
\text { Maximum number of latent variables: 15 } \\
\text { Selection of the number of latent variables: } R^{2} \text { differences between two consecutive less } \\
\text { than 2\% }\end{array}$ \\
\hline
\end{tabular}

Supplementary table 2: Optimal models for the VNIR depending on the sample and the discrimination method

\begin{tabular}{|l|l|l|l|l|l|l|l|}
\hline Sample & Performances & DT & RF & ANN & LDA & QDA & PLS-DA \\
\hline Allos & Processing & CLAHE & Detrend & CLAHE & CLAHE & CLAHE & CLAHE \\
\hline
\end{tabular}




\begin{tabular}{|c|c|c|c|c|c|c|c|}
\hline & \multirow{2}{*}{$\begin{array}{l}\text { Neurons } \\
\text { Accuracycal }_{\text {cal }}\end{array}$} & & & \multicolumn{4}{|l|}{2} \\
\hline & & 0.978 & 0.886 & 0.889 & 0.863 & 0.860 & 0.840 \\
\hline & Accuracypred & 0.828 & 0.882 & 0.890 & 0.889 & 0.889 & 0.879 \\
\hline & Qualitative & 3 & 3 & 3 & 2 & 2 & 2 \\
\hline & Computation time (s) & 42.544 & 1272.513 & 263.840 & 8.086 & 251.592 & 12.975 \\
\hline \multirow{6}{*}{ Bourget } & Processing & Raw & Raw & Raw & Raw & Raw & Raw \\
\hline & Neurons & & & 2 & & & \\
\hline & Accuracycal $_{\text {cal }}$ & 0.999 & 0.996 & 0.996 & 0.994 & 0.994 & 0.993 \\
\hline & Accuracypred & 0.994 & 0.995 & 0.996 & 0.993 & 0.992 & 0.991 \\
\hline & Qualitative & 2 & 3 & 2 & 2 & 2 & 2 \\
\hline & Computation time (s) & 1.817 & 139.542 & 5.174 & 1.216 & 54.210 & 2.057 \\
\hline \multirow{6}{*}{ Geneva } & Processing & Detrend & Detrend & Detrend & Detrend & Detrend & Detrend \\
\hline & Neurons & & & 2 & & & \\
\hline & Accuracy $_{\text {cal }}$ & 0.998 & 0.990 & 0.992 & 0.987 & 0.987 & 0.985 \\
\hline & Accuracy pred & 0.987 & 0.993 & 0.994 & 0.989 & 0.989 & 0.985 \\
\hline & Qualitative & 2 & 2 & 2 & 3 & 3 & 3 \\
\hline & Computation time (s) & 2.615 & 200.019 & 16.167 & 1.142 & 52.417 & 2.814 \\
\hline
\end{tabular}

Supplementary table 3: Optimal models for the SWIR depending on the sample and the discrimination method

\begin{tabular}{|c|c|c|c|c|c|c|c|}
\hline Sample & Performances & DT & $\mathrm{RF}$ & ANN & LDA & QDA & PLS-DA \\
\hline \multirow{6}{*}{ Allos } & Processing & Raw & SNV & Autoscale & Raw & Raw & SNV \\
\hline & Neurons & & & 3 & & & \\
\hline & Accuracy $_{\text {cal }}$ & 0.982 & 0.925 & 0.922 & 0.920 & 0.920 & 0.900 \\
\hline & Accuracypred & 0.876 & 0.928 & 0.935 & 0.927 & 0.926 & 0.902 \\
\hline & Qualitative & 3 & 5 & 5 & 5 & 5 & 5 \\
\hline & Computation time (s) & 1.214 & 95.740 & 6.989 & 0.664 & 39.287 & 0.800 \\
\hline \multirow{6}{*}{ Bourget } & Processing & Detrend & Detrend & Detrend & Detrend & Detrend & Detrend \\
\hline & Neurons & & & 2 & & & \\
\hline & Accuracy $_{\text {cal }}$ & 0.994 & 1.000 & 0.976 & 0.971 & 0.972 & 0.969 \\
\hline & Accuracy ${ }_{\text {pred }}$ & 0.952 & 0.959 & 0.967 & 0.954 & 0.955 & 0.958 \\
\hline & Qualitative & 2 & 3 & 4 & 5 & 5 & 5 \\
\hline & Computation time (s) & 0.266 & 10.402 & 0.402 & 0.167 & 24.268 & 0.219 \\
\hline
\end{tabular}




\begin{tabular}{|c|c|c|c|c|c|c|c|}
\hline \multirow{6}{*}{ Geneva } & Processing & SNV & SNV & SNV & SNV & SNV & SNV \\
\hline & Neurons & & & 2 & & & \\
\hline & Accuracy $_{\text {cal }}$ & 0.998 & 1.000 & 0.996 & 0.992 & 0.992 & 0.991 \\
\hline & Accuracypred & 0.991 & 0.993 & 0.993 & 0.989 & 0.988 & 0.987 \\
\hline & Qualitative & 3 & 4 & 4 & 5 & 5 & 5 \\
\hline & Computation time (s) & 0.155 & 5.436 & 0.255 & 0.113 & 21.478 & 0.163 \\
\hline
\end{tabular}

Supplementary table 4: Optimal models for the VNIR-SWIR depending on the sample and the discrimination method

\begin{tabular}{|c|c|c|c|c|c|c|c|}
\hline Sample & Performances & DT & $\mathrm{RF}$ & ANN & LDA & QDA & PLS-DA \\
\hline \multirow{6}{*}{ Allos } & Processing & CLAHE & SNV & SNV & Raw & Raw & SNV \\
\hline & Neurons & & & 2 & & & \\
\hline & Accuracy $_{\text {cal }}$ & 0.984 & 0.943 & 0.933 & 0.931 & 0.931 & 0.901 \\
\hline & Accuracypred & 0.877 & 0.931 & 0.940 & 0.935 & 0.935 & 0.921 \\
\hline & Qualitative & 3 & 5 & 4 & 5 & 5 & 5 \\
\hline & Computation time (s) & 2.726 & 86.900 & 15.562 & 1.097 & 49.604 & 1.206 \\
\hline \multirow{6}{*}{ Bourget } & Processing & Raw & Raw & Raw & Detrend & Detrend & Raw \\
\hline & Neurons & & & 2 & & & \\
\hline & Accuracy $_{\text {cal }}$ & 0.993 & 1.000 & 0.981 & 0.979 & 0.979 & 0.979 \\
\hline & Accuracypred & 0.966 & 0.967 & 0.970 & 0.969 & 0.969 & 0.968 \\
\hline & Qualitative & 1 & 2 & 2 & 3 & 4 & 4 \\
\hline & Computation time (s) & 0.372 & 15.082 & 0.672 & 0.265 & 26.742 & 0.276 \\
\hline \multirow{6}{*}{ Geneva } & Processing & Raw & Raw & Raw & Raw & Raw & Raw \\
\hline & Neurons & & & 2 & & & \\
\hline & Accuracycal $_{\text {cal }}$ & 0.999 & 1.000 & 0.998 & 0.997 & 0.993 & 0.991 \\
\hline & Accuracy ${ }_{\text {pred }}$ & 0.996 & 0.996 & 0.996 & 0.993 & 0.991 & 0.993 \\
\hline & Qualitative & 2 & 2 & 4 & 4 & 4 & 4 \\
\hline & Computation time (s) & 0.223 & 17.307 & 0.758 & 0.437 & 52.612 & 0.404 \\
\hline
\end{tabular}

